\title{
The True Nature of the Adductor Brevis Dually Innervated by the Anterior and Posterior Branches of the Obturator Nerve in Humans
}

\author{
By
}

\author{
Masahiro MIURA, Eijiro NAKAMURA, Seiji KATO, Takeshi USUI and \\ Ryosuke MIYAUCHI*
}

\begin{abstract}
Department of Anatomy, Oita Medical University, 1-1, Idaigaoka, Hasama-machi, Oita-gun, Oita, 879-55, Japan,
* Department of Anatomy, Fukuoka University School of Medicine, 7-45-1, Nanakuma, Jonan-ku, Fukuoka, 814-01, Japan
\end{abstract}

- Received for Publication, March 22, $1994-$

Key Words: Adductor brevis, Obturator nerve, Dual innervation, Gross anatomy

\begin{abstract}
Summary: To clarify the true nature and the mechanism of the human adductor brevis (specific adductor brevis, SAB) innervated dually by the anterior and posterior branches of the obturator nerve, we have carried out gross anatomical examination of 100 body halves of 50 adult Japanese cadavers.

The SAB was found in 23 of the 100 thighs $(23.0 \%)$, and its anterior and posterior surfaces received respectively the twigs from the anterior branch of the obturator nerve and the filament(s) from the posterior branch. The filament(s) was either indirectly derived from the medial stratum of the posterior branch through the formation of a common trunk with the twigs distributed in the obturator externus (14/23 thighs, $60.9 \%)$ or directly originating in the medial stratum of the posterior branch of the obturator nerve $(9 / 23$ thighs, $39.1 \%)$. In the close examination of the intramuscular distribution of the nerve to the SAB, the region innervated by the anterior branch of the obturator nerve could cleary be distinguished from that innervated by the posterior branch. The obturator nerve received fibers from L1234 (2/23 thighs) or from L234 (21/23 thighs), and the posterior branch of the obturator nerve ran through the obturator externus (18/23 thighs, $78.3 \%)$ or ran over the obturator externus $(5 / 23$ thighs, $21.7 \%)$, and finally emerged into the thigh.

In view of the mode of origin of the filament(s), the structural element of the filament(s), and the pattern of entry of the filament(s) into the SAB, the fasciculus of the SAB, which is innervated by the posterior branch of the obturator nerve, was considered to originate in the obturator externus. Thus, the true nature of the SAB was concluded to be a complex product which was formed by a mechanism in which the fasciculus, which had separated from the obturator externus during the process of ontogeny, fused secondarily to the posterior surface of the regular adductor brevis. From findings in our series of studies, it was estimated that the maximum frequency of occurrence of the $\mathrm{SAB}$ could be $56 \%$. Furthermore, from a statistical point of view, the segmental composition or course of the obturator nerve is not considered to be related to either the formation or the incidence of this muscle.
\end{abstract}

The topographic-anatomical relationship between the anteromedial muscle group of the thigh and the obturator nerve has been the subject of intense investigative effort during the past century (Macalister, 1871; Testut, 1892; Loth, 1912; Frohse \& Fränkel, 1913). These reports, except that of Frohse \& Fränkel (1913), provide general information on the origin and insertion of the muscle and its adhesion to neighbouring muscles concerned, but they do not address its nerve supply. Some investigators have stated that the adductor brevis usually receives, at its anterior surface, twigs from the anterior branch of the obturator nerve and occasionally receives, at its posterior surface, filament(s) from the posterior branch of the nerve (Bardeen, 1907; Hasue, 1958; Tozinbara, 1960). However, they did not discuss the true nature and mechanism of formation of this dually innervated muscle. Therefore, the true nature of this muscle and mechanism of its formation still remains to be elucidated. We previously reported a supernumerary muscle occurring between the adductors brevis and minimus in humans (Nakamura et al. 1992).

In this context, the present study was undertaken to determine the morphological characteristics of the adductor brevis dually innervated by the anterior and posterior branches of the obturator nerve and tentatively called here the specific adductor brevis (SAB). Moreover, two questions were proposed: 1) Why have various figures for the incidence of the SAB been reported by different investigators? 2) How are the segmental composition of the obturator nerve and its course related to the incidence of the $\mathrm{SAB}$ ? We here describe the topographic-anatomical 
relationships of the $\mathrm{SAB}$ to its nerve supply and discuss the true nature and the mechanism of formation of the SAB.

\section{Materials and Methods}

The materials and dissection methods used were the same as those described previously (Nakamura et al. 1992). All SAB structures found in this study were dissected out in the form of a nerve-muscle specimen, and the intramuscular distribution of the supplying nerves in each specimen was examined under a stereomicroscope.

\section{Results}

The SAB was found in 23 of the 100 thighs examined (incidence, $23.0 \%$ ) (Table 1). By definition, the adductor brevis that is innervated only by the anterior branch of the obturator nerve, namely the regular adductor brevis, is abbreviated as $\mathrm{RAB}$ below.

The SAB, like the RAB, unexceptionally arose from the upper part of the inferior ramus of the pubis, ran obliquely downwards and laterally while

Table 1. Incidence of the adductor brevis dually innervated by the anterior and posterior branches of the obturator nerve (SAB)

\begin{tabular}{lc}
\hline Investigator (material) & $\begin{array}{c}\text { Incidence } \\
\% \text { (No. found/No. thighs) }\end{array}$ \\
\hline $\begin{array}{l}\text { Bardeen (1907) } \\
\text { (unknown races, adults) }\end{array}$ & $2.3(2 / 88)$ \\
$\begin{array}{l}\text { Hasue (1958) } \\
\text { (Japanese fetuses) } \\
\begin{array}{l}\text { Tozinbara (1960) } \\
\text { (Japanese fetuses) }\end{array}\end{array}$ & $5.7(2 / 35)$ \\
$\begin{array}{l}\text { Present authors } \\
\text { (Japanese adults) }\end{array}$ & $43.8(14 / 32)$ \\
\hline
\end{tabular}

gradually increasing in width, and was inserted into the upper third of the medial lip of the linea aspera of the femur.

Like the RAB, the insertion of the SAB had either a single digitation (3/23 thighs, $13.0 \%)$ or double digitations (20/23 thighs, $87.0 \%)$. In the case of double digitations, the insertion aponeurosis was split by twigs from the deep branches of the medial circumflex femoral artery and vein.

Figure 1 shows the pattern of entry of the anterior and posterior branches of the obturator nerve into the $\mathrm{SAB}$. The obturator nerve innervating the $\mathrm{SAB}$ received fibers from L1234 (first, second, third and fourth lumbar nerves) in 2 of the 23 thighs or from L234 in 21 of the 23 thighs (Table 2). The obturator nerve emerged through the medial side of the psoas major to enter the pelvic cavity and ran downwards and forwards along the inner surface of the pelvic wall. It divided into the anterior and posterior branches before entering the obturator canal. After passing through the obturator canal, the anterior branch either passed through the obturator externus $(12 / 23$ thighs, $52.2 \%)$ or ran over the upper margin of the obturator externus (11/23 thighs, $47.8 \%)$, and finally emerged in the thigh. In the thigh, the anterior branch to the $\mathrm{SAB}$, like the anterior branch supplying the RAB, ran between the pectineus and the obturator externus, then between the adductors longus and brevis, while being divided into several terminal branches. One of these branches was divided into several twigs entering the anterior surface of the SAB. The posterior branch of the obturator nerve, on the other hand, after giving off several twigs to the obturator externus, ran through the obturator canal, then either perforated the obturator externus (18/23 thighs, $78.3 \%)$ or ran over its upper margin $(5 / 23$ thighs, $21.7 \%)$, and finally emerged into the thigh (Table 4). In the thigh, the posterior branch ran between the pectineus and the obturator externus, and then was divided into several terminal branches while running between the $\mathrm{SAB}$ and the adductor miniums. The SAB was innervated by the

Table 2. Segmental composition of the obturator nerve of the Japanese adults (present authors)

\begin{tabular}{|c|c|c|c|c|c|}
\hline $\begin{array}{l}\text { Root of the } \\
\text { Obt. nerve }\end{array}$ & Thigh with the SAB & $\begin{array}{l}\text { Thigh with a supernumerary } \\
\mathrm{m} \text {. between the adductors } \\
\text { brev. and min. }\end{array}$ & Usual thigh* & & tal \\
\hline L 1234 & 2 cases & 4 cases & 5 cases & \multicolumn{2}{|c|}{11 cases $(11.0 \%)$} \\
\hline L 234 & 21 & 25 & 30 & 76 & $(76.0 \%)$ \\
\hline L 2345 & 0 & 2 & 3 & 5 & $(5.0 \%)$ \\
\hline L 34 & 0 & 2 & 2 & 4 & $(4.0 \%)$ \\
\hline \multirow[t]{2}{*}{ L 345} & 0 & 0 & 4 & 4 & $(4.0 \%)$ \\
\hline & 23 & 33 & 44 & 100 & \\
\hline
\end{tabular}

* Thigh with neither a supernumerary muscle nor the SAB. 
Table 3. Segmental composition of the obturator nerve of the Japanese adults (Isii, 1936; Matsuyama, 1950; Hokanishi \& Koshya, 1957)

\begin{tabular}{|c|c|c|c|c|c|c|}
\hline \multirow{3}{*}{$\begin{array}{l}\begin{array}{l}\text { Root of the } \\
\text { obturator nerve }\end{array} \\
\text { L } 23 \\
234\end{array}$} & \multirow{2}{*}{\multicolumn{2}{|c|}{$\frac{\begin{array}{c}\text { Isii } \\
(134 \text { thighs })\end{array}}{1 \text { case }(\mathrm{s})(0.7 \%)}$}} & \multirow{2}{*}{\multicolumn{2}{|c|}{$\begin{array}{c}\begin{array}{c}\text { Matsuyama } \\
(80 \text { thighs })\end{array} \\
1 \text { case(s) }(1.3 \%)\end{array}$}} & \multirow{2}{*}{\multicolumn{2}{|c|}{$\begin{array}{c}\begin{array}{c}\text { Hokanishi \& } \\
\text { Koshya } \\
(83 \text { thighs })\end{array} \\
1 \text { case(s) }(1.2 \%)\end{array}$}} \\
\hline & & & & & & \\
\hline & 89 & $(66.4 \%)$ & 58 & $(72.5 \%)$ & 65 & $(78.3 \%)$ \\
\hline L 2345 & 0 & (0) & 1 & $(1.3 \%)$ & 0 & (0) \\
\hline L 34 & 42 & $(31.3 \%)$ & 14 & $(17.5 \%)$ & 14 & $(16.9 \%)$ \\
\hline L 345 & 2 & $(1.5 \%)$ & 6 & $(7.5 \%)$ & 3 & $(3.6 \%)$ \\
\hline
\end{tabular}

Table 4. Topographic-anatomical relationship between the posterior branch of the obturator nerve and the obturator externus of the Japanese adults (present authors)

\begin{tabular}{lccr}
\hline & $\begin{array}{c}\text { Post. branch of the } \\
\text { obt. nerve running } \\
\text { over the obt. ext. }\end{array}$ & $\begin{array}{l}\text { Post. branch of the } \\
\text { obt. nerve running } \\
\text { through the obt. ext. }\end{array}$ & Total \\
\hline $\begin{array}{l}\text { Thigh with the SAB: A } \\
\text { Thigh with a supernumerary m. }\end{array}$ & 5 cases & 18 cases & 23 cases \\
$\begin{array}{l}\text { between the adductors brev. } \\
\text { and min.: B }\end{array}$ & 8 & 25 & 33 \\
$\begin{array}{l}\text { Usual thigh: } \mathrm{C}^{*} \\
\end{array}$ & 17 & 27 & 44 \\
& 30 & 70 & 100 \\
\hline
\end{tabular}

*: Thigh with neither a supernumerary muscle nor the SAB.

filament(s) from the posterior branch at its posterior surface. The filament(s) either originated from the medial stratum of the posterior branch through the formation of a common trunk with the twigs distributed in the obturator externus (14/23 thighs, $60.9 \%$ ) (Fig. 2a and b) or derived directly from the medial stratum of the posterior branch ( $9 / 23$ thighs, $39.1 \%$ ) (Fig. 3a and b).

Stereomicroscopic findings of the intramuscular distribution of the anterior and posterior branches of the obturator nerve: Intramuscular communication was observed between the anterior and posterior branches in one case, but the remaining 22 cases showed no such communication. The anterior branch was distributed in the ventral fasciculus of the entire muscle regardless of its terminal morphology, single digitation or double digitations, whereas the distribution of the posterior branch was restricted to the fasciculus in the vicinity of the locus of invasion. The fasciculi innervated by the anterior and posterior branches could be distinguished relatively clearly from each other (Fig. 4).

\section{Discussion}

1) The true nature of the $S A B$

Before discussing the true nature and the mechanism of formation of the SAB, it is necessary to identify the regular adductor brevis (RAB). We previously described the characteristics of the RAB in detail (Nakamura et al. 1992) and have stated that the RAB is sandwiched by the anterior and posterior branches of the obturator nerve and receives the twigs from the anterior branch at its anterior surface. We stated also that the adductor brevis innervated only by the posterior branch of the obturator nerve, which has been reported by Bardeen, 1907 ( 5 cases), by Hasue, 1958 (1 case) and by Moghaddam, 1963 ( 1 case), cannot be regarded as the RAB. Thus, the $\mathrm{SAB}$ should be considered to be a complex product formed with the $\mathrm{RAB}$ and an unknown fasciculus.

The true nature of anomalous muscle has conventionally been studied by two methods. One is the method based on the topographic-anatomical relationship between anomalous muscle and its nerve supply (Eisler, 1912; Sato, 1971; Kasai \& Chiba, 1977; Kato \& Sato, 1978; Sato, 1980; Miyauchi, 1983; Yamada, 1986; Koizumi, 1989; Sakamoto, 1989), and the other is that based on the topographic 
relationship between anomalous muscle and adjacent muscles (Ruge, 1905). Since a muscle can usually maintain the most stable relationship with innervating nerves, it is reasonable to discuss the true nature of anomalous muscle on the basis of the relationship to its nerve supply. Therefore, we discuss below the true nature of the $\mathrm{SAB}$ based on its topographicanatomical relationship to its supplying nerves.

As stated above, the SAB was found by us in 23 of the 100 thighs. In 14 of the 23 thighs $(60.9 \%)$, the $\mathrm{SAB}$ is not only innervated from its anterior surface by the muscular twigs originating from the anterior branch of the obturator nerve but also innervated from its posterior surface by the filament(s) arising from one of the twigs which originate from the medial stratum of the posterior branch of the obturator nerve and are distributed in the obturator externus (Fig. 2a and b). Thus, the fasciculus of the $\mathrm{SAB}$, which is innervated by the posterior branch, is thought to be the fasciculus derived from the obturator externus from the viewpoints of the origin of the filament(s) and its entry into the muscle.

In 9 other thighs $(39.1 \%)$, since the filament(s) derived directly from the posterior branch enters the $\mathrm{SAB}$ from its posterior surface, the fasciculus innervated by the filament(s) cannot simply be considered to have originated from the obturator externus. However, the filament(s) in each of these nine cases originates from the medial stratum of the posterior branch and enters the SAB from its posterior surface in a manner similar to that of the filament(s) in the other 14 cases (Fig. 3a and b). On the basis of the pattern of entry of the filament(s) into the SAB and the point of origin of the filament(s) in the posterior branch, the fasciculus innervated by the filament(s) from the posterior branch is considered to be derived also from the obturator externus.

It is therefore concluded that the true nature of the $\mathrm{SAB}$ is a complex produced by a mechanism in which the fasciculus, which has separated from the obturator externus to become independent, has fused to the posterior surface of the $\mathrm{RAB}$ during the process of ontogeny.

Whether the SAB-fasciculus innervated by a posterior branch is derived from the adductor minimus is also discussed below. Before to discussing this, the topographic-anatomical relationship between the posterior branch of the obturator nerve and the adductor minimus must be elucidated first. It has been widely reported that the posterior branch of the obturator nerve emerges into the thigh through the obturator canal, and then runs distally along the anterior surface of the adductors minimus and magnus to give off several twigs to both muscles from their anterior surface (Bühler, 1904; Bardeen,
1907; Frohse \& Fränkel, 1913; Braus \& Elze, 1960; Tozinbara, 1960; Moghaddam, 1963; Hollinshead, 1974; Williams et al. 1989). In the present study, the posterior branch of the obturator nerve was found to run distally along the anterior surfaces of the adductors minimus and magnus in all 100 thighs and to supply the several twigs to the adductor minimus from their anterior surfaces (Figs $5 a, b$ and $6 a, b$ ). These twigs arose from the lateral stratum of the posterior branch of the obturator nerve. Moreover, in 4 of the 100 thighs, the posterior branch of the obturator nerve supplied a twig from its medial stratum to the posterior surface of the adductor minimus. We presently regard the muscle in the above four cases as a structure in which the superficial fasciculus separated from the obturator externus fused with the posterior surface of the pure adductor minimus. The true nature of the adductor minimus receiving twigs from the posterior branch at its anterior and posterior surfaces will be discussed later.

Thus, the pure adductor minimus may be located on the dorsal side of the posterior branch and may receive twigs from the lateral stratum of the posterior branch at its anterior surface. If it is assumed that the superficial fasciculus separated from the adductor minimus and fused with the dorsal side of the RAB, this fasciculus would be situated on the dorsal side of the posterior branch of the nerve and would receive twigs from the posterior branch at its anterior surface. Moreover, since the twigs innervating the adductor minimus originate in the lateral stratum of the posterior branch, the twigs innervating the superficial fasciculus of the adductor minimus must originate also from the lateral stratum of the posterior branch. However, the fasciculus of the SAB, which was innervated by the posterior branch, was located on the ventral side of the posterior branch as stated in Results, and received the filament(s) from the medial stratum of the posterior branch at its posterior surface. Thus, on the basis of the topographicanatomical relationship between the posteriorbranch-innervated fasciculus of the $\mathrm{SAB}$ and the posterior branch of the obturator nerve and also on the basis of the pattern of the origin of the supplying nerve, the posterior-branch-innervated fasciculus of the SAB cannot be derived from the adductor minimus.

2) Relationship of the $\mathrm{SAB}$ to the supernumerary muscle occurring between the adductors brevis and minimus

We previously reported that the supernumerary muscle frequently (incidence, $33 \%$ ) occurs between the adductors brevis and minimus (Nakamura et al. 1992). Both the supplying branch for the 
supernumerary muscle and that for the superficial fasciculus of the obturator externus arise from the medial stratum of the posterior branch of the obturator nerve, and occasionally from a common trunk. When these branches independently originate from the posterior branch, their sites of origin are very close to each other. Thus, these branches are homologous to each other or very closely related. From this relationship between these branches, we consider that the supernumerary muscle has its origin in the obturator externus.

As mentioned in the previous section, based on the mode of the nerve supply, the fasciculus of the SAB innervated by the posterior branch of the obturator nerve is considered to be derived also from the obturator externus. In conclusion, the fasciculus of the SAB supplied by the posterior branch of the obturator nerve and the supernumerary muscle should be considered to be homologous to each other.

Kodama (1986) and Kida (1990) have suggested that the muscular branches arising from the same stratum of a nerve trunk are essentially distributed in the muscular components of the same series, and the closer is the relation between the muscular branches, the closer are their sites of origin in the nerve trunk. These findings of Kodama and Kida support our concept that the supernumerary muscle and the fasciculus of the SAB innervated by the posterior branch of the obturator nerve are homologous to each other.

The anterior surface of the supernumerary muscle is separated from the posterior surface of the RAB by the fascia and twigs from the deep branch of the medial circumflex femoral artery and vein. It is widely accepted that the course of blood vessels and the pattern of their distribution to muscles exhibit great variations. Therefore, if blood vessels do not run between the supernumerary muscle and the $\mathrm{RAB}$ and if there is little fascia (connective tissue) between the supernumerary muscle and the RAB, both muscles can easily fuse with each other. On this basis, we consider that the $\mathrm{SAB}$ is a complex produced by the fusion of the supernumerary muscle with the posterior surface of the RAB (Figs. 5a, b and $6 a, b)$.

In our close examination of the intramuscular distribution of nerves supplying the $\mathrm{SAB}$, the regions in which the anterior and posterior branches of the obturator nerve were distributed could clearly be distinguished from each other. This finding also support our concept stated above.

The superficial fasciculus of the obturator externus is thought to be intrinsically unstable. This fasciculus frequently separates from the obturator externus and becomes independent (this was observed in 56 of the 100 thighs $(56 \%)$ in our study), and either maintains its independence depending upon the developmental state of adjacent organs (supernumerary muscle, in 33 of the 100 thighs [33\%] in our study) or fuses secondarily to the posterior surface of the RAB (SAB, in 23 out of the 100 thighs).

It is stated in Gray's Anatomy (Williams et al. 1989) that the adductor brevis is innervated by the posterior branch of the obturator nerve whenever it is not innervated by the anterior branch of the obturator nerve, but it is impossible for this to occur in the light of our findings.

\section{3) The incidence of occurrence of the $\mathrm{SAB}$}

We found the SAB in 23 of the 100 thighs $(23 \%)$. The incidence of the $\mathrm{SAB}$ as reported in previous studies is shown in Table 1.

As mentioned in the preceding section, the superficial fasciculus is separated from the obturator externus at a frequency of $56 \%$. Thus, it is possible that the $\mathrm{SAB}$ is also produced at a maximum incidence of $56 \%$ or at a minimum incidence of $0 \%$ depending upon the developmental state of the adjacent organs. On the other hand, the incidence of occurrence of the supernumerary muscle decreases as the incidence of the SAB rises; that is, the sum of the incidence of the $\mathrm{SAB}$ and that of the supernumerary muscle should be $56 \%$. The figures for the incidence of occurrence of the SAB reported by Bardeen (1907) and Hasue (1958) are extremely low, compared with ours. Moreover, these investigators paid no attention to the suppernumerary muscle appearing between the adductors brevis and minimus.

Hokanishi (1957) reported that the mean diameter of the twigs that were derived from the anterior branch of the obturator nerve and were distributed in the adductor brevis in adult human cadavers was only $853 \mu \mathrm{m}$. When the adductor brevis is dually innervated by the anterior and posterior branches of the obturator nerve, the filament(s) from the posterior branch is much thinner than the twigs from the anterior branch. It is possible, therefore, that Bardeen and Hasue missed the filament(s) from the posterior branch. The incidence of occurrence of the SAB reported by Tozinbara (1960) is higher than ours. However, he did not include the supernumerary muscle and it is possible that he overlooked it. If the supernumerary muscle is taken into account, then the incidence of occurence of the SAB might approach $56 \%$.

4) Relationship of the course of the posterior branch and the segmental composition of the obturator nerve to the formation of the SAB.

The anterior branch of the obturator nerve will 
not be discussed further because it is not particularly important for the formation of the SAB.

The topographic-anatomical relationship between the posterior branch of the obturator nerve and the obturator externus is shown in Table 4.

The thighs observed in the present study are divided into the following three groups: group $A$, thighs with the SAB; group $B$, thighs with a supernumerary muscle appearing between the adductors brevis and minimus; and group $\mathrm{C}$, other thighs (referred to below as usual thighs). Then, whether the course of the posterior branch of the obturator nerve affects the incidence of the SAB was statistically examined by using the chi-square test for independence. No significant differences were found between the groups $A$ and $C\left(X^{2}=1.955\right)$, between groups $A$ and $B\left(X^{2}=0.048\right)$, between groups $B$ and $C\left(X^{2}=1.782\right)$ or between groups $A+B$ and $C$ $\left(X^{2}=2.791\right)$. From a statistical point of view, it is concluded therefore that the presence or absence of the posterior branch running through the obturator externus has no influence on the incidence of the SAB.

The segmental composition of the obturator nerve obtained in the present study is shown in Table 2, and the relevant information reported by other investigators is presented in Table 3 . The results in Tables 2 and 3 resemble each other. Moreover, the segmental compositions of the obturator nerve and their incidence in thighs with the $\mathrm{SAB}$ are also similar to those in usual thighs. Therefore, the segmental composition of the obturator nerve is thought to have little effect on the incidence of the SAB.

On the basis of the above findings and discussion, we propose the following as the true nature and the mechanism of formation of the SAB. Because of the intrinsic instability of the superficial fasciculus of the obturator externus, this fasciculus often separates from this muscle during the process of ontogeny, and appears as an independent structure between the adductors brevis and minimus as observed in 56 of the 100 thighs. Depending upon the developmental condition of the adjacent organs, this fasciculus maintains its independence (as in 33 of the 100 thighs) or secondarily fuses with the posterior surface of the RAB (as in 23 of the 100 thighs). Thus, the $\mathrm{SAB}$ is thought to be a complex produced by the fusion of the RAB and the superficial fasciculus of the obturator externus.

\section{Acknowledgements}

The authors are grateful to Mr. T. Kajiware and Mr. S. Tatsukawa for their skillful technical assistance, and to Mrs. M. Maki for her secretarial help.

\section{References}

1) Bardeen, CR. Development and variation of the nerves and the musculature of the inferior extremity and of the neighboring regions of the trunk in man. Am. J. Anat., 1907;6:259-390.

2) Braus, H. and Elze, C. Die Leitungsbahnen der unteren Extremität. Anatomie des Menschen. Bd. III, 2. Aufl. 197-244, Springer, Berlin, Göttingen, Heidelberg, 1960.

3) Bühler, A. Morphologie des M, adductor magnus und Adduktorenschlitz beim Menschen. Gegenbaurs Morphol. Jahrb., 1904;32:1-20.

4) Eisler, P. Die Muskeln des Stammes. Gustav Fischer Jena 1912.

5) Frohse, F. and Fränkel, M. Spezieller Teil. Die Muskeln des menschlichen Beines. 443-619, Gustav Fischer, Jena, 1913.

6) Hasue, M. Aduktora-muskoloj kaj ilia nervoj ce japanaj fetoj (in Japanese with Esperanto abstract). J. Nippon Med. Sch., 1958;17:228-235.

7) Hokanishi, H. Studies on distribution of nerves over each of the pelvic joint, (part 1) on nerve distribution over pubic symphysis (a supplement; distribution of nerves over pyramidalis muscle) (in Japanese with English abstract). Med. J. Kagoshima Univ., 1957;9:149-163.

8) Hokanishi, H. and Koshya, M. Lumbar plexus of South Kyushu Japanese (in Japanese with English abstract). Med. J. Kagoshima., 1957;30:310-320.

9) Hollinshead, WH. Buttock, Thigh, and Hip Joint. The Abdomen. The Pelvis. Textbook of Anatomy, 3rd ed. 366-422, 557-674, 677-723, Harper \& Row, New York, 1974.

10) Ishii, K. Ueber den Plexus lumbalis der Bewohner von Kyushu (Japan) (in Japanese with German abstract). J. Kumamoto Med. Soc., 1936;12:1005-1016.

11) Kasai, T. and Chiba, S. True nature of the muscular arch of the axilla (in Japanese with English abstract). Acta Anat. Nippon., 1977;52:309-336.

12) Kato, K. and Sato, T. Morphological analysis of the levator scapulae, rhomboideus and serratus anterior (in Japanese with English abstract). Acta Anat. Nippon., 1978;53:339356.

13) Kida, M. Stratum-structure of the spinal nerves in the understanding of body structure (in Japanese with English abstract). Acta Anat. Nippon., 1990;65:75-82.

14) Kodama, K. Morphological significance of the supracostal muscles, and the superficial intercostal nerve - a new definition (in Japanese with English abstract). Acta Anat. Nippon., 1986;61:107-129.

15) Koizumi, M. A morphological study on the coracobrachialis muscle (in Japanese with English abstract). Acta Anat. Nippon., 1989;64:18-35.

16) Loth, E. Muskel der hinteren (unteren) Gliedmaße. Beiträge zur Anthropologie der Negerweichteile (Muskelsystem). 181-229, Streker \& Schröder, Stuttgart, 1912.

17) Macalister, A. Additional observations on muscular anomalies in human anatomy (third series), with a catalogue of the principal muscular variations hitherto published. Transact Roy. Irish. Acad, 1871;25:1-134.

18) Matuyama, T. Über den Plexus lumbalis bei Japanern. Folia Psychiatr. Neurol. Jpn., 1950;4:230-286.

19) Miyauchi, R. Abnormal nerve supply of the $M$. obliquus externus abdominis in man. Acta Anat. Nippon., 1983:58: 
$518-525$.

20) Moghaddam, TC. Variationen des N. obturatorius und N. obturatorius accessorius. Anat. Anz., 1963;113:1-18.

21) Nakamura, E, Masumi, S, Miura, M, Kato, S. and Miyauchi, R. A supernumerary muscle between the adductors brevis and minimus in humans. Okajimas Folia Anat. Jpn., 1992;69: 89-98.

22) Ruge, G. Der Hautrumpfmuskel der Säugetiere-M. sternalis und Achselbogen des Menschen. Gegenbaurs Morphol. Jahrb., 1905;33:379-531.

23) Sakamoto, H. Anatomical study of the ramification and intramuscular distribution of the intercostal nerves in man (in Japanese with English abstract). Acta Anat. Nippon., 1989;64:126-163.

24) Sato, K. A morphological analysis of the nerve supply of the sphincter ani externus, levator ani and coccygeus (in Japanese with English abstract). Acta Anat. Nippon., 1980;55:187223.
25) Sato, T. The levatores costarum and their nerve supply in man. A contribution to the morphology of the paravertebral muscles (in Japanese with English abstract). Acta Anat. Nippon., 1971:46:172-192.

26) Testut, L. Les anomalies musculaires chez l'homme, G. Masson, Paris, 1892.

27) Tozinbara, M. Studies on the nerve distribution to the muscles of the lower limb of the Japanese. II. Distribution of the muscular branches to the muscles of the thigh (in Japanese with English abstract). Med. J. Kagoshima Univ., 1960;11: 2534-2557.

28) Williams, PL, Warwick, R, Dyson, $M$. and Bannister, LH. Neurology. Gray's Anatomy. 37th ed., 859-1243, Churchill Livingstone, London, Melbourne \& New York, 1989.

29) Yamada, T. Re-evaluation of the flexor digitorum superficialis (in Japanese with English abstract). Acta Anat. Nippon., 1986;61:283-298. 


\section{Explanation of Figures}

\begin{tabular}{lll}
\multicolumn{3}{c}{ Abbreviations } \\
A : anterior branch of obturator nerve & LT : lesser trochanter \\
AB : adductor brevis & OE : obturator externus \\
AL : adductor longus & OM : obturator membrane \\
AMa : adductor magnus & ON : obturator nerve \\
AMi : adductor minimus & P : posterior branch of obturator nerve \\
C : cutaneous branch & Pe : pectineus \\
FN : femoral nerve & RAB : regular adductor brevis \\
F : femur & SAB : specific adductor brevis \\
G : gracilis & SF : superficial fasciculus of obturator externus \\
HJ : hip joint & TP : tubercle of pubis
\end{tabular}

\section{Explanation of Figures}

Plate I

Fig. 1. Anterior view. Distribution pattern of the filament(s) (dotted lines) derived from the posterior branch of the obturator nerve, which is supplied to the SAB from its posterior surface.

Type I: distribution to upper digitation of the SAB

Type II: distribution to middle portion of the SAB

Type III: distribution to both digitations of the SAB

Type IV: distribution to lower digitation of the SAB 
True Nature of Dually Innervated Adductor Brevis 75

Type 1

(14/23thighs, 60.8\%)

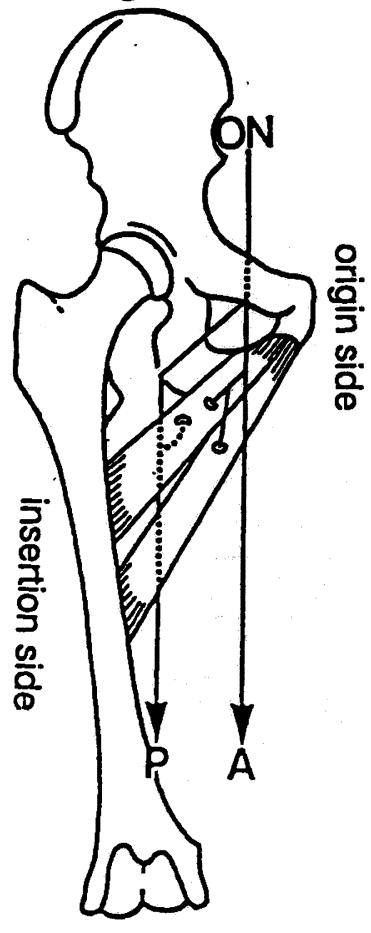

Type III

(2/23thighs, 8.7\%)

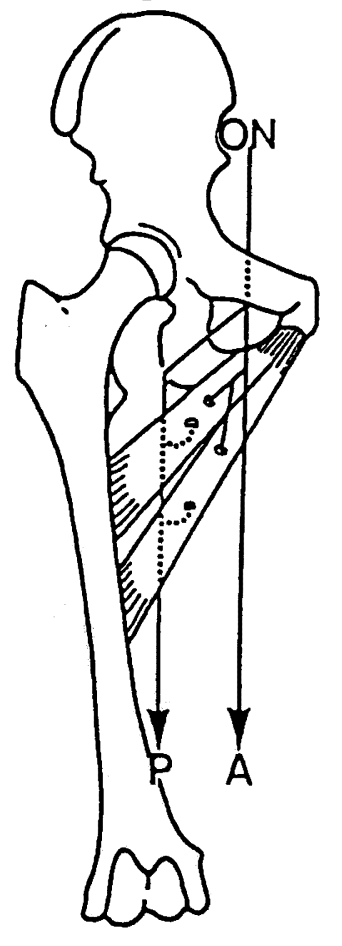

Type II

(1/23thighs, 4.4\%)

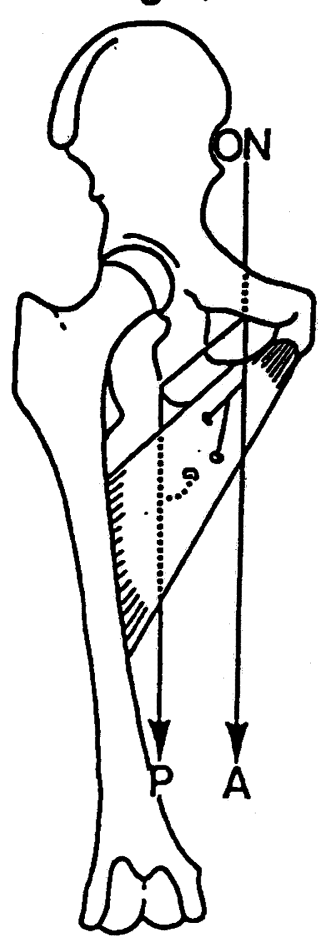

Type IV

(6/23thighs, 26.1\%)

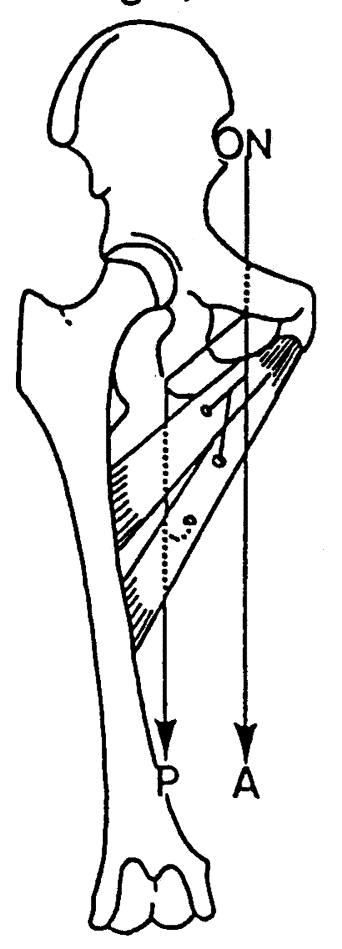




\section{Plate II}

Fig. 2a and b. Anterior view. The pectineus, iliopsoas and quadriceps femoris have been removed. The adductor longus is reflected medially and downwards. The superior ramus of the pubis has been partially removed, so as to expose the anterior and posterior branches of the obturator nerve.

a: The twigs (arrowheads) derived from the anterior branch are supplied to the SAB from its anterior surface.

b: The SAB and the superficial fasciculus of the obturator externus have been reflected medially and laterally respectively. Some of the twigs from the posterior branch are indicated by the small underlying pieces of black paper. The SAB is innervated, from its posterior surface, by a filament (arrow) derived from one of the twigs being supplied to the superficial fasciculus of the obturator externus. 

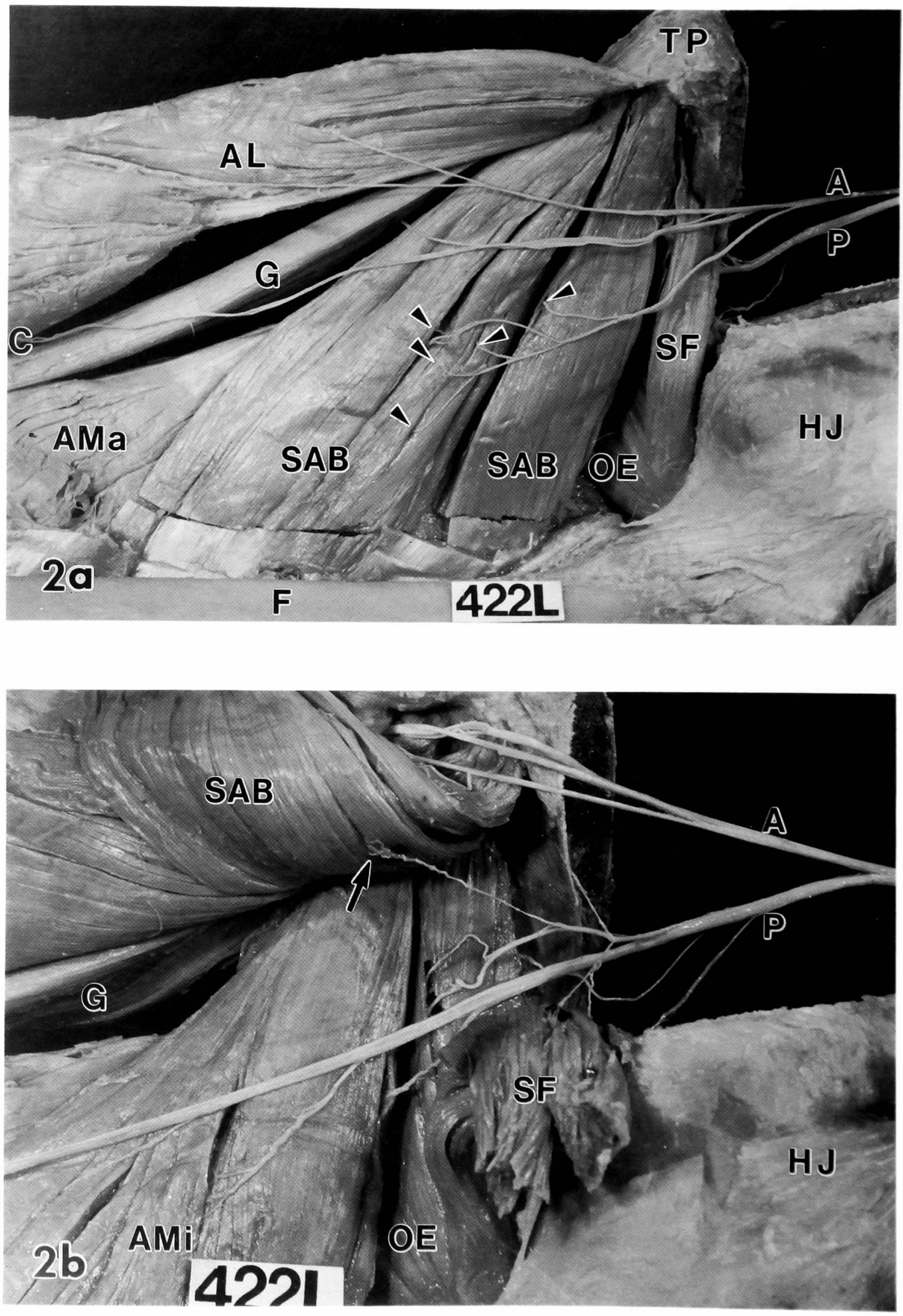


\section{Plate III}

Fig. 3a and $\mathrm{b}$. Anterior view. The pectineus, illiopsoas and quadriceps femoris have been removed. The adductor longus has been reflected medially. The superior ramus of the pubis has been partially removed, so as to expose the anterior and posterior branches of the obturator nerve.

a: The twigs (arrowheads) derived from the anterior branch are supplied to the SAB from its anterior surface.

b: The adductor brevis and superficial fasciculus of the obturator externus have been reflected medially and laterally, respectively. The anterior branch has been medially displaced. The SAB is innervated, from its posterior surface, by a filament (arrow) directly originating from the posterior branch, and the site of its origin is close to that of the twig being supplied to the superficial fasciculus of the obturator externus. The filament for the SAB is indicated by a small underlying piece of black paper. 

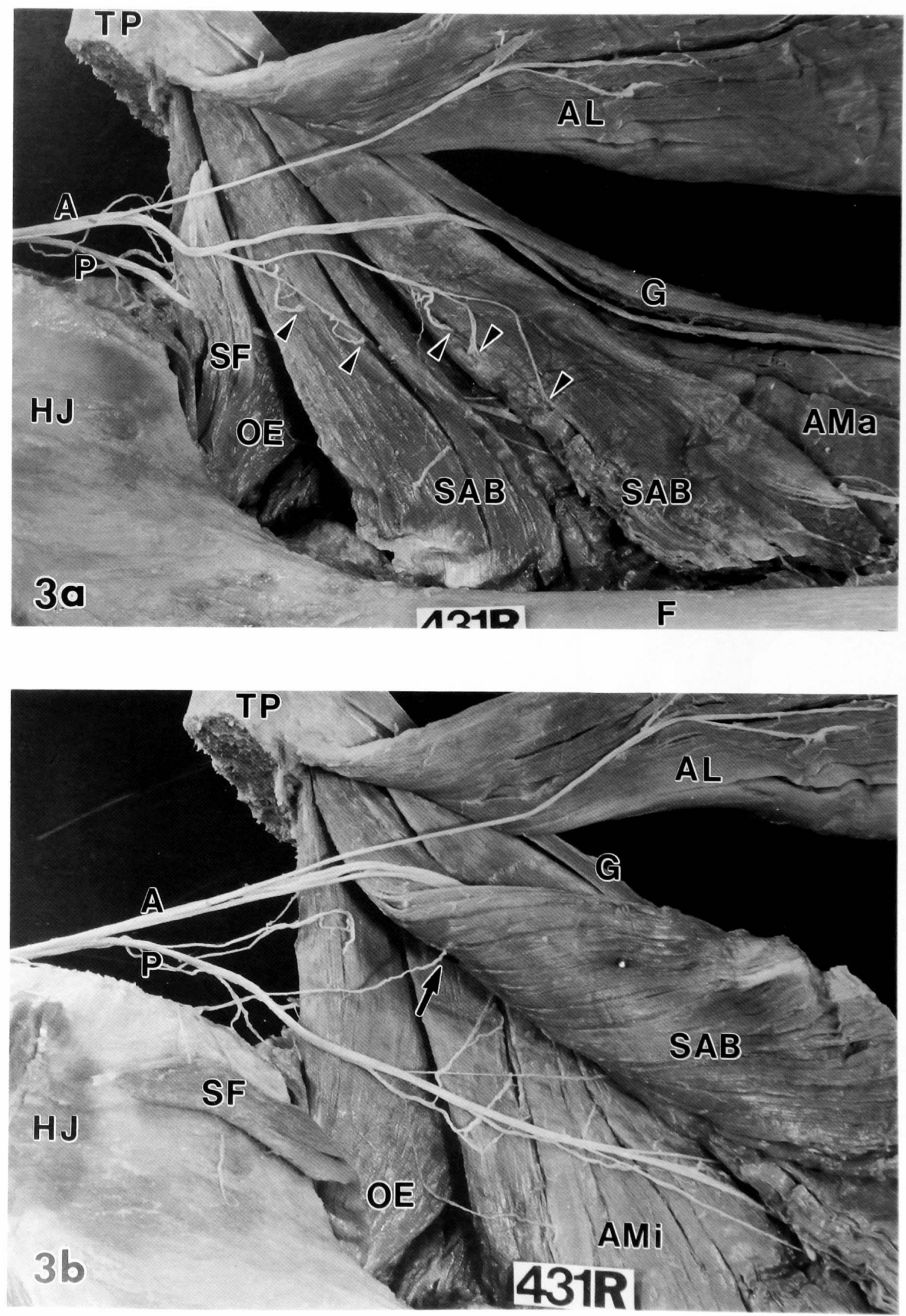
Plate IV

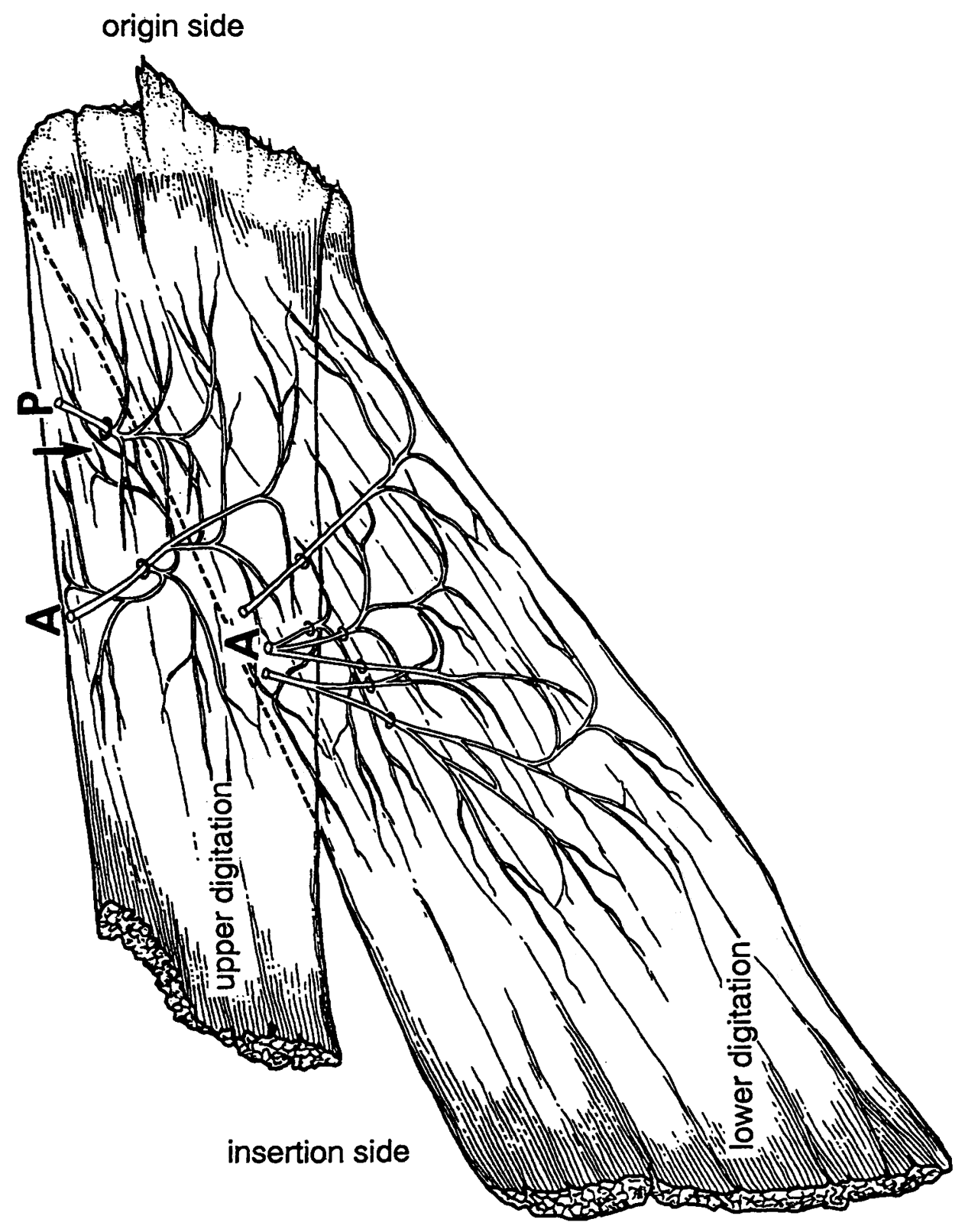

Plate IV

Fig. 4. Intramuscular distribution of the obturator nerve to the SAB (Cadaver No. 311R). Dorsal aspect. The arrow indicates the duplicate distribution of the twigs from the anterior and posterior branches of the obturator nerve. No intramuscular communication is observed between the anterior and posterior branches. The posterior branch is distributed in the limited region of the deep fasciculus of the SAB, whereas the anterior branches are distributed in the entire superficial fasciculus. 

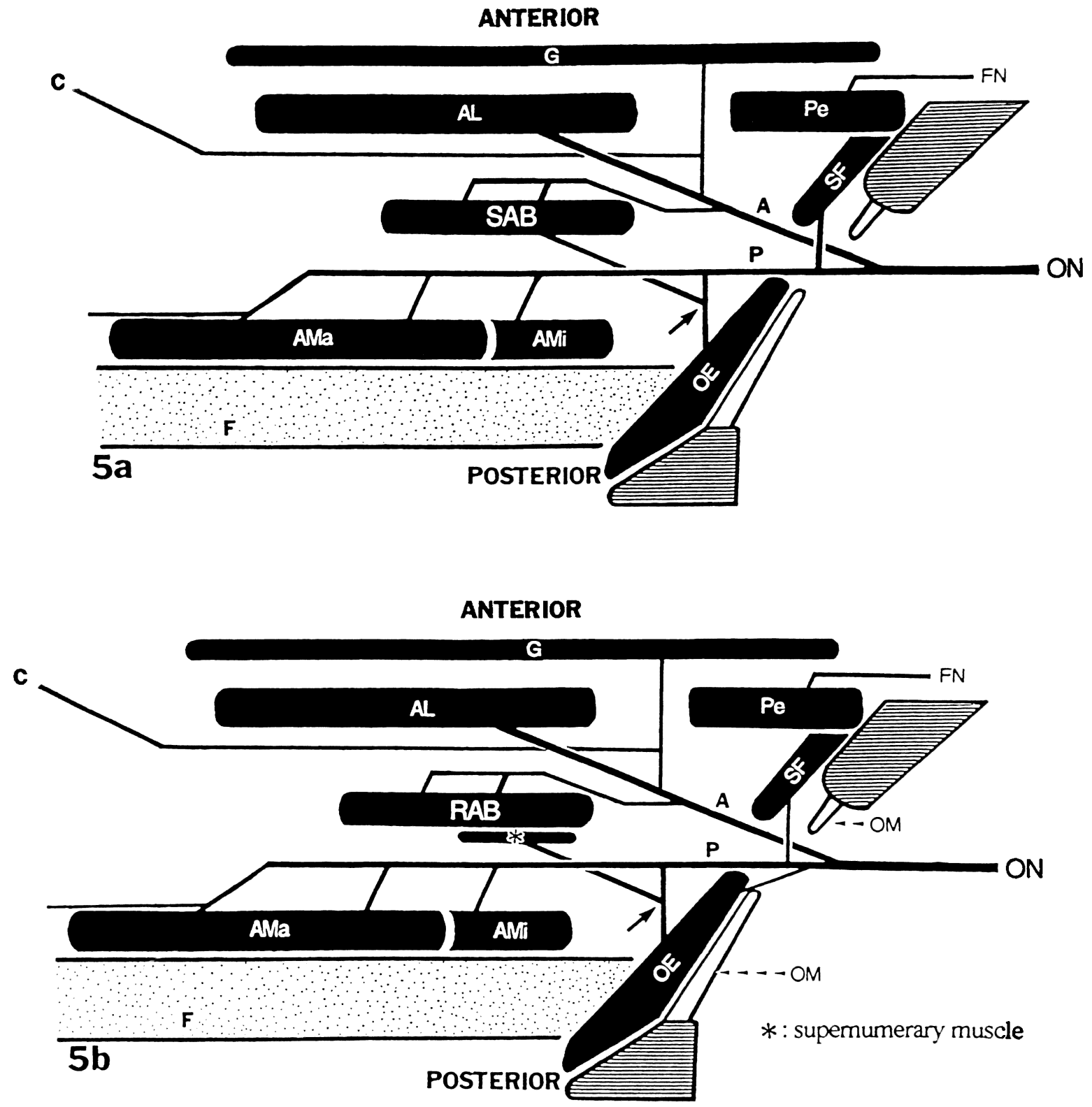

Plate V

Fig. 5a and $\mathrm{b}$. Diagrams of the topographic-anatomical relationship between the anteromedial muscle group and the obturator nerve. The filament (arrow in a) entering the SAB from its posterior surface is derived from muscular twigs for the obturator externus. as the filament (arrow in b) to the supernumerary muscle dose. 
Plate VI
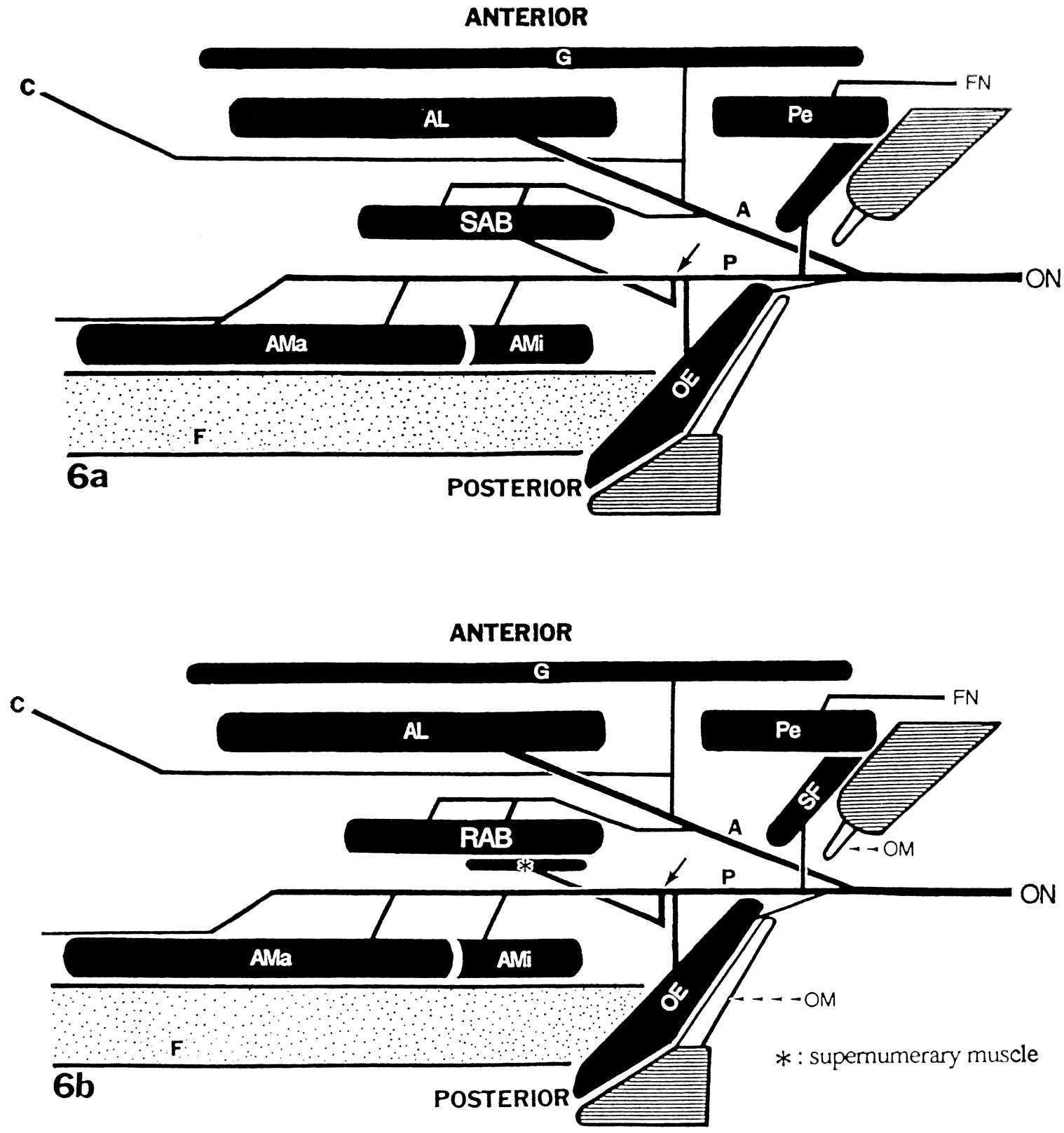

Plate VI

Fig. 6a and b. Diagrams of the topographic-anatomical relationship between the anteromedial muscle group and the obturator nerve. The site (arrow in a) of origin of the SAB-filament in the posterior branch, like the filament to the supernumerary muscle (arrow in b), is close to that of the twigs to the obturator externus. 